\title{
Farelo de licuri em dietas para alevinos de tambaqui (Colossoma Macropomum, Cuvier, 1818)
}

[Licuri meal in diets for tambaqui (Colossoma Macropomum, Cuvier, 1818)]

D.F.B. Campeche ${ }^{1}$, J.F.B. Melo ${ }^{2}$, L. Balzana ${ }^{3}$, R.C. Souza ${ }^{4}$, R.A.C.R. Figueiredo ${ }^{3}$

${ }^{1}$ Embrapa Semiárido - Petrolina, PE

${ }^{2}$ Universidade Federal do Vale do São Francisco - Petrolina, PE

${ }^{3} 3^{\text {a }}$ Superintendência Regional da Companhia de Desenvolvimento do Vale do São Francisco - Petrolina, PE

${ }^{4}$ Aluna de pós-graduação - Universidade Federal do Vale do São Francisco - Petrolina, PE

\section{RESUMO}

A busca de alimentos alternativos para a fabricação de ração para peixes tem se tornado constante. No entanto, é essencial que, além de ter ótimo aproveitamento pela espécie, este alimento esteja disponível ao longo do ano. Deste modo, o objetivo do presente trabalho foi avaliar o efeito da substituição do farelo de milho pelo farelo de licuri sobre o desempenho de alevinos de tambaqui. Três tratamentos de níveis de substituição de milho pelo farelo de licuri $(33,33 \% ; 66,66 \%$ e $100 \%)$ foram avaliados e comprados com a

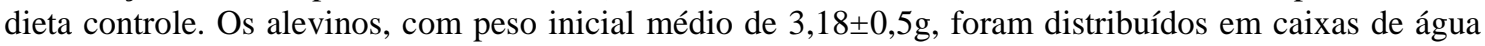
de 250L, contendo cada uma, inicialmente, 16 animais. Os alevinos foram alimentados três vezes ao dia, a uma taxa de 5\% da biomassa total, durante o período de 50 dias. A cada 10 dias eram realizadas biometrias. Ao final do experimento, foram avaliados parâmetros de desempenho zootécnico e foi feita avaliação bromatológica da carcaça. Não houve diferença significativa entre os tratamentos, para os parâmetros: peso final, ganho de peso, conversão alimentar, eficiência alimentar, sobrevivência e crescimento, somente para o consumo de ração, que foi significativamente menor quando houve $100 \%$ de substituição. Neste tratamento também houve maior porcentagem de proteína bruta e menor teor de extrato etéreo na carcaça.

Palavras-chave: substituição, milho, nutrição, carcaça, crescimento

\begin{abstract}
The search for alternative ingredients for fish feed has become constant, therefore it is essential that the ingredients have total use by the specie. Beyond this, the ingredient should be available throughout the year. The aim of this study was to evaluate the effect of the corn meal replacement by licuri meal over tambaqui juvenile performance. Three replacement treatments were evaluated and compared to the control diet (33.33\%; 66.66\% and 100\%). Sixteen fish (initial weight $=3.18 \pm 0.5 \mathrm{~g}$ ) were placed in 250 $L$ tanks. Fish were fed three times a day at the average of $5 \%$ of total biomass. Every ten days fish were weighed and measured. At the end of the trial, performance and carcass composition were evaluated in each treatment. There was no significant difference among treatments for final weight, weight gain, feed conversion, feed efficiency, survival and growth. However, there was significant difference for feed consumption, which was significantly lower where 100\% of corn meal was replaced by licuri meal. Is this treatment higher carcass protein content and lower carcass fat was also significant.
\end{abstract}

Keywords: replacement; corn; nutrition; carcass; growth

\section{INTRODUÇÃO}

A necessidade de exploração e uso sustentável dos recursos naturais do semiárido brasileiro é

Recebido em 4 de julho de 2012

Aceito em 5 de setembro de 2013

E-mail: daniela.campeche@cpatsa.embrapa.br imperativa, tendo em vista a realidade de adaptação no setor agropecuário no atual cenário de mudanças climáticas. Muitas são as opções de espécies vegetais nativas próprias para aproveitamento agropecuário, entre elas o licuri 
ou ouricuri, que é o fruto de uma palmeira (Syagrus coronata (Mart.) Becc.). O coproduto da extração por prensagem do óleo é o farelo de licuri. O óleo é utilizado para fabricação de saponáceos e cosméticos. O farelo, por sua vez, é utilizado na alimentação animal, principalmente de ruminantes.

Por ser rústico e se alimentar na natureza de frutos de palmeiras, o tambaqui é uma espécie que, nutricionalmente, aproveita de modo satisfatório o coproduto citado (Oliveira et al., 2006). Entre as características de rusticidade da espécie está o fato de ela suportar ambientes eutrofizados e se desenvolver bem neles, como é próprio de açudes e barragens no semiárido (Campeche et al., 2009; Lima et al., 2009). Além dos fatores supracitados, o tambaqui é uma espécie muito apreciada em comunidades do semiárido brasileiro não só por possuir sabor agradável, mas também por ser uma espécie própria para o cultivo em açudes dependentes de água de chuva.

Avaliações de produtos e coprodutos de origem vegetal disponíveis no semiárido brasileiro têm sido objetivo de alguns estudos (Miranda et al., 2009; Santos et al., 2010; Pezzato et al., 2009). Alguns desses alimentos, como, por exemplo, o farelo de algaroba, já estão sendo usados na composição de rações comerciais. A busca por alternativas em termos de ingredientes para rações de peixes é altamente desejável, uma vez que esse insumo representa, aproximadamente, 60 a $70 \%$ do custo de produção na piscicultura (Cyrino et al., 2004). É importante que os produtos e coprodutos avaliados estejam disponíveis em quantidades e com preço que sejam atrativos para as fábricas de rações (Hisano e Portz, 2007). Desta forma, eles poderão ser incluídos em rações comerciais e aumentar a sustentabilidade da piscicultura local, além de aumentar a geração de renda e trabalho no semiárido brasileiro, evitando o êxodo rural.

A fase de alevinagem tem como característica o rápido crescimento dos animais e é nessa fase que se observam melhores respostas em relação a diferentes alimentos. O objetivo deste trabalho foi avaliar o efeito da substituição do farelo de milho pelo farelo de licuri sobre o desempenho de alevinos de tambaqui (Colossoma macropomum Cuvier, 1818).

\section{MATERIAL E MÉTODOS}

O ensaio ocorreu na Estação de Piscicultura de Bebedouro, que pertence à $3^{\text {a }}$ Superintendência Regional da Companhia de Desenvolvimento do Vale do São Francisco, em Petrolina-PE (Codevasf). Foram utilizadas 12 caixas d'água de $100 \mathrm{~L}$, em um sistema de recirculação aberto, como unidade experimental. Cada caixa continha 16 alevinos $(3,18 \pm 0,5 \mathrm{~g})$, distribuídos em delineamento inteiramente ao acaso. Os tratamentos, com três repetições cada, consistiram de dietas contendo três níveis de substituição do farelo de milho pelo farelo de licuri $(33,33 \% ; 66,66 \%$ e $100 \%)$, além de uma dieta controle sem a substituição do farelo de milho. Os alevinos foram alimentados três vezes ao dia ( $08 \mathrm{~h} 00 ; 11 \mathrm{~h} 30 ; 15 \mathrm{~h} 45)$, a uma taxa de $5 \%$ da biomassa total, durante o período de 50 dias. A cada 10 dias eram realizadas biometrias para acompanhamento do desempenho e ajuste da ração a ser fornecida. Diariamente, as caixas foram sifonadas como manutenção da limpeza do ambiente.

O farelo de licuri, alimento avaliado neste trabalho, é coproduto da extração do óleo de licuri, a qual ocorre em comunidades do semiárido nordestino. Uma amostra do alimento foi retirada para avaliação bromatológica no Laboratório de Nutrição da Embrapa Semiárido, por meio de metodologias de rotina (Tab. 1). Esse alimento foi misturado, nas devidas proporções, aos demais ingredientes que compuseram as dietas experimentais (Tab. 2). Após a junção dos ingredientes secos de cada tratamento, foram adicionados $50 \%$ do peso total de água à mistura, e esta foi homogeneizada em um misturador para panificação. A mistura foi peletizada em um moedor de carnes, usando-se anel de diâmetro $0,5 \mathrm{~mm}$. Os pellets formados foram levados à estufa de recirculação forçada a $60^{\circ} \mathrm{C}$ por 24 horas. Após serem retiradas, as dietas foram quebradas em tamanhos menores, armazenadas em sacos plásticos e estocadas em um freezer até o início do experimento. Uma amostra da dieta relativa a cada tratamento foi retirada para avaliação bromatológica no Laboratório de Nutrição da Embrapa Semiárido (Tab. 1). 
Tabela 1. Valor bromatológico das dietas experimentais e do farelo de licuri

\begin{tabular}{lccccc} 
& \multicolumn{3}{c}{ Porcentagem de inclusão de farelo de licuri } & Farelo de licuri \\
\cline { 2 - 5 } & $0,00 \%$ & $33,33 \%$ & $66,66 \%$ & $100,00 \%$ & \\
\cline { 2 - 5 } Matéria seca (\%) & 96,17 & 95,25 & 95,48 & 96,78 & 95,63 \\
Cinza (\%) & 8,69 & 9,02 & 6,44 & 9,88 & 5,6 \\
Proteína bruta (\%) & 32,39 & 33,41 & 34,78 & 34,93 & 22,51 \\
Extrato etéreo (\%) & 6,55 & 7,30 & 7,62 & 8,18 & 16,99 \\
\hline
\end{tabular}

Tabela 2. Composição centesimal das dietas experimentais

\begin{tabular}{lcccc} 
& \multicolumn{3}{c}{ Porcentagem de inclusão de farelo de licuri } \\
Ingredientes & $0,00 \%$ & $33,33 \%$ & $66,66 \%$ & $100,00 \%$ \\
\hline Farelo de soja & 62,13 & 62,13 & 62,13 & 62,13 \\
Farelo de milho & 30,00 & 20,00 & 10,00 & - \\
Farelo de licuri & - & 9,99 & 19,99 & 30,00 \\
Fosfato bicálcico & 3,03 & 3,03 & 3,03 & 3,03 \\
Óleo de soja & 2,23 & 2,23 & 2,23 & 2,23 \\
Premix vitamínico mineral ${ }^{1}$ & 2,00 & 2,00 & 2,00 & 2,00 \\
Sal (NaCl) & 0,50 & 0,50 & 0,50 & 0,50 \\
DL-metionina & 0,10 & 0,10 & 0,10 & 0,10 \\
BHT $^{2}$ & 0,01 & 0,01 & 0,01 & 0,01 \\
\hline
\end{tabular}

${ }^{1}$ Composição do premix vitamínico mineral: composição por quilo de produto (composition per kg the product): vit. $\mathrm{A}=1.200 .000 \mathrm{UI}$; vit. $\mathrm{D} 3=200.000 \mathrm{UI}$; vit. $\mathrm{E}=12.000 \mathrm{mg}$; vit. $\mathrm{K} 3=2400 \mathrm{mg}$; vit. $\mathrm{B} 1=4800 \mathrm{mg}$; vit. $\mathrm{B} 2=4800 \mathrm{mg}$; vit. B6 = 4000mg; vit. B12 = 4800mg; ác. fólico (folic acid) =1200mg; pantotenato de cálcio (calcium pantothenate) $=12.000 \mathrm{mg}$; vit. $\mathrm{C}=48.000 \mathrm{mg}$; biotina (biotin) $=48 \mathrm{mg}$; colina $($ choline $)=65.000 \mathrm{mg}$; ácido nicotínico (nicotinic acid $)=24.000 \mathrm{mg} ; \mathrm{Fe}=10.000 \mathrm{~g} ; \mathrm{Cu}=600 \mathrm{mg} ; \mathrm{Mn}=4000 \mathrm{mg} ; \mathrm{Zn}=6000 \mathrm{mg} ; \mathrm{I}=20 \mathrm{mg} ; \mathrm{Co}=2 \mathrm{mg}$ e $\mathrm{Se}=20 \mathrm{mg}$.

${ }^{2}$ BHT: butil-hidroxitolueno.

Ao final do experimento, foram avaliados os parâmetros de desempenho zootécnico: peso final, ganho de peso (peso final - peso inicial), consumo de ração, conversão alimentar aparente (consumo de ração/ganho de peso), eficiência alimentar (ganho de peso/consumo de ração), sobrevivência (número de peixes final - número de peixes inicial) e comprimento total. Todos os peixes de cada tratamento foram eviscerados para avaliação da composição bromatológica da carcaça. Essas análises também foram realizadas no Laboratório de Nutrição Animal da Embrapa Semiárido. Todos os dados foram submetidos à análise de variância (ANOVA) e, posteriormente, ao teste de Tukey $(\mathrm{P}<0,05)$ para comparação de médias.
Os parâmetros de qualidade de água: oxigênio dissolvido (mg. $\left.1^{-1}\right)$, temperatura $\left({ }^{\circ} \mathrm{C}\right)$ e $\mathrm{pH}$ foram monitorados diariamente com o uso de equipamentos digitais, como prática de rotina laboratorial e para manutenção do nível da qualidade de água ótima para cultivo de alevinos de tambaqui.

\section{RESULTADOS E DISCUSSÃO}

Os resultados da avaliação de desempenho relativa aos diferentes tratamentos avaliados podem ser observados na Tab. 3. Não houve diferença significativa no peso final e no ganho de peso entre os diferentes tratamentos avaliados $(\mathrm{P}<0,05)$. Este resultado também foi observado quando o milho foi substituído em até $60 \%$ por 
milheto em dietas para alevinos de tambaqui (Silva et al., 1997). Alevinos de tambaqui que se alimentaram de ração contendo resíduo de cervejaria, com valor de $\mathrm{PB}$ na ração de $36 \%$, tiveram peso final e ganho de peso significativamente menores quando comparados com alevinos que receberam rações comerciais extrusadas, com valor de PB de 34\% (Cruz et al., 1997). O mesmo resultado foi observado quando alevinos de tambaqui foram alimentados com farinha de vagem de algaroba em substituição ao milho (Miranda et al., 2009). Tais resultados comprovam que tanto o licuri quanto a algaroba podem ser utilizados em rações comerciais pela espécie. Alevinos de tilápia que receberam dietas contendo farelo de nabo forrageiro em substituição à soja não mostraram diferença significativa no ganho de peso, até o nível de $25 \%$ de substituição (Santos et al., 2009). Mesmo sendo de hábito fitoplanctófago, alevinos de tilápia têm peso final maior quando recebem alimentação de origem animal, em comparação à alimentação de origem vegetal (Davis et al., 2010; Leal et al., 2010). Assim sendo, os resultados citados acima indicam que os alimentos alternativos, utilizados nas rações, bem como a proporção de inclusão e a forma da ração, influenciam no peso final e no ganho de peso, independentemente da espécie.

Tabela 3. Índices de desempenho (média \pm desvio-padrão) de tambaqui alimentado com valores crescentes de inclusão de farelo de licuri

\begin{tabular}{|c|c|c|c|c|c|c|}
\hline & \multicolumn{4}{|c|}{ Porcentagem de inclusão de farelo de licuri } & \multirow{2}{*}{ Equação de regressão } & \multirow{2}{*}{$\mathrm{R}^{2}$} \\
\hline & $0 \%$ & $33,33 \%$ & $66,66 \%$ & $100,00 \%$ & & \\
\hline $\begin{array}{l}\mathrm{PF} \\
(\mathrm{g})\end{array}$ & $31,72 \pm 2,81$ & $32,95 \pm 1,33$ & $30,31 \pm 1,74$ & $27,84 \pm 0,5$ & & \\
\hline $\begin{array}{l}\text { GP } \\
(\mathrm{g})\end{array}$ & $26,59 \pm 5,03$ & $27,88 \pm 4,94$ & $24,78 \pm 4,74$ & $23,37 \pm 2,29$ & & \\
\hline $\begin{array}{l}\text { CR } \\
(\mathrm{g})\end{array}$ & $49,98 \pm 6,72 \mathrm{AB}$ & $51,72 \pm 4,04 \mathrm{AB}$ & $55,32 \pm 3,62 \mathrm{~A}$ & $44,76 \pm 0,88 \mathrm{~B}$ & $\begin{array}{c}-0,0028 x^{2}+0,2406 x \\
+49,179\end{array}$ & 0,79 \\
\hline CAA & 1,89 & 1,88 & 2,2 & 1,93 & & \\
\hline EA & 0,53 & 0,54 & 0,44 & 0,52 & & \\
\hline $\begin{array}{c}S \\
(\%)\end{array}$ & 87,5 & 85,41 & 89,58 & 87,5 & & \\
\hline $\begin{array}{l}\mathrm{CT} \\
(\mathrm{cm})\end{array}$ & $12,67 \pm 0,28$ & $12,21 \pm 0,22$ & $11,75 \pm 0,13$ & $11,53 \pm 0,24$ & & \\
\hline
\end{tabular}

Médias com letras diferentes na linha apresentam diferenças significativas pelo teste de Tukey $(\mathrm{P}<0,05)$. $\mathrm{PF}-$ peso final. GP - ganho de peso. CR - consumo de ração. CAA - conversão alimentar aparente. EA - eficiência alimentar. $\mathrm{S}$ - sobrevivência. CT - comprimento total.

O consumo de ração no tratamento em que houve $100 \%$ de substituição foi menor $(\mathrm{P}<0,05)$, sem, entretanto, afetar os demais parâmetros produtivos. Este resultado demonstra que o farelo de milho pode ser substituído pelo farelo de licuri em até $100 \%$, sem afetar o desempenho de alevinos até o peso final médio de 30 gramas. Há vantagem na substituição por haver menor consumo de ração pelos peixes, o que pode implicar menor custo de produção. Outros coprodutos, como o farelo de vagem da algaroba, também podem substituir em até $100 \%$ o farelo de milho, sem influenciar no consumo de ração de alevinos de tambaqui (Miranda et al., 2009; Pezzato et al., 2009). Diferentemente do tambaqui, alevinos de tilápia apresentam consumo de ração significantemente maior quando as rações possuem maior quantidade de ingrediente de origem animal, em comparação com ingrediente de origem vegetal (Davis et al., 2010). Essa diferença entre as espécies é em razão do diferente hábito alimentar delas.

As taxas de conversão alimentar e eficiência alimentar avaliadas neste estudo também não apresentaram diferença significativa quando comparadas entre os diferentes tratamentos. O mesmo resultado foi relatado por Miranda et al. (2009), quando avaliaram a inclusão de farinha de algaroba em até $100 \%$ de substituição ao farelo de milho. Guimarães e Storti-Filho (2004) utilizaram produtos agrícolas e florestais, fornecidos moídos e de forma não balanceada, como alimentação suplementar para alevinos de tambaqui e registraram taxas de conversão alimentar de 12:1. Esse resultado comprova que 
ingredientes não convencionais têm de ser utilizados de forma balanceada mesmo para cultivos de subsistência. A conversão alimentar aparente em alevinos de tambaqui foi também maior quando estes foram alimentados com ração contendo resíduo de cervejaria, em comparação com alevinos que receberam ração comercial, no entanto sem diferença significativa (Cruz et al., 1997). Alevinos de tilápia que recebem até $25 \%$ de inclusão de nabo forrageiro na dieta, em substituição à soja, também não apresentam diferença significativa na taxa de conversão alimentar (Santos et al., 2009). Esses resultados também comprovam que a quantidade, a digestibilidade e o tipo de alimento alternativo utilizado influenciam na conversão alimentar independentemente da espécie cultivada.

Não houve diferença significativa na taxa de sobrevivência até o final do experimento. Maior mortalidade foi observada no início do experimento, e tal fato é creditado ao manejo inicial, à mortalidade ocorrida e não à influência dos diferentes tratamentos. Resultados semelhantes foram observados em alevinos de tambaqui e tilápia (Cruz et al., 1997; Miranda et al., 2009; Leal et al., 2010). Semelhantemente, não houve diferença significativa no comprimento total entre os diferentes tratamentos. Cruz et al. (1997) observaram que alevinos de tambaqui alimentados com ração comercial tiveram comprimento total expressivamente maior do que os que foram alimentados com dietas contendo resíduo de cervejaria. Quando não há diferença no comprimento total entre tratamentos distintos avaliados, pode-se concluir que as diferentes porcentagens de alimento alternativo ingerido estão fornecendo, de forma proporcional, energia para o crescimento corporal e para a energia metabólica, durante o período experimental.

A alta porcentagem de extrato etéreo do farelo de licuri pode ter afetado de forma positiva o valor desse nutriente nas rações, como pode ser observado nos resultados de desempenho. Como é de conhecimento que frutos de palmeiras fazem parte do hábito alimentar natural do tambaqui, é natural que a espécie aproveite muito bem o alto valor energético desses alimentos (Oliveira et al., 2006). Modificações nas fontes de energia dietética do tambaqui levam a mudanças na fisiologia e no metabolismo digestivo da espécie (Correa et al., 2007). Essas mudanças nos comportamentos fisiológico e metabólico do tambaqui em relação a alterações na dieta alimentar fazem parte da característica adaptativa da espécie, o que favorece as formulações comerciais de rações em relação à disponibilidade e ao preço de alimentos no mercado.

Os resultados apresentados na Tab. 4 mostram que houve influência da inclusão do farelo do licuri na composição centesimal da carcaça do tambaqui. Semelhantemente, Silva et al. (2003) avaliaram o uso de frutos da região amazônica em alevinos de tambaqui e observaram a influência da composição proximal dos frutos na porcentagem de nutrientes das dietas experimentais.

O valor de umidade e matéria seca na carcaça foi afetado pelo nível de inclusão do farelo de licuri, mas não de forma linear. De igual modo, o nível de substituição de farelo de soja por nabo forrageiro em tilápia-do-nilo afetou o valor de umidade dos filés, mas também não de forma linear (Santos et al., 2009). Alevinos de tilápia que se alimentaram com diferentes valores de inclusão de hidrolisado proteico não mostraram diferença nos valores de matéria seca na carcaça (Leal et al., 2009). Conforme observado nos parâmetros de desempenho zootécnico, o tipo de alimento e a sua porcentagem podem afetar diferentes espécies de forma diversa.

O maior valor de proteína bruta na carcaça foi detectado nos alevinos que receberam $100 \%$ de inclusão de farelo de licuri. Este resultado pode indicar que a proteína disponível no licuri está sendo utilizada de forma satisfatória para atender às exigências metabólicas do tambaqui e também para promover o crescimento muscular. Semelhantemente, o nível de inclusão de um ingrediente proteico na dieta de alevinos de tilápia afeta o valor de proteína na composição da carcaça (Leal et al., 2009). Entretanto, o aumento no nível de inclusão do farelo de nabo forrageiro em substituição ao farelo de soja não altera significativamente o valor de proteína em filés de tilápia-do-nilo (Santos et al., 2009). 
Tabela 4. Composição centesimal da carcaça de tambaqui alimentado com valores crescentes de inclusão de farelo de licuri

\begin{tabular}{lccccccc} 
& \multicolumn{2}{c}{ Porcentagem de inclusão de farelo de licuri } & & \multirow{2}{*}{ Equação de regressão } & \multirow{2}{*}{$\mathrm{R}^{2}$} \\
\cline { 2 - 5 } & $0 \%$ & $33,33 \%$ & $66,66 \%$ & $100,00 \%$ & & \\
\hline U & $72,47 \mathrm{a}$ & $75,34 \mathrm{c}$ & $73,96 \mathrm{~b}$ & $73,36 \mathrm{~b}$ & $-0,0008 \mathrm{x}^{2}+0,0819 \mathrm{x}+72,722$ & 0,70 \\
$\mathrm{MS}$ & $27,53 \mathrm{c}$ & $24,66 \mathrm{a}$ & $26,04 \mathrm{~b}$ & $26,64 \mathrm{~d}$ & $0,0008 \mathrm{x}^{2}-0,0819 \mathrm{x}+27,278$ & 0,70 \\
$\mathrm{~PB}$ & $58,85 \mathrm{~b}$ & $59,32 \mathrm{~b}$ & $57,47 \mathrm{a}$ & $61,36 \mathrm{c}$ & $0,0008 \mathrm{x}^{2}-0,0599 \mathrm{x}+59,253$ & 0,58 \\
$\mathrm{EE}$ & $22,52 \mathrm{c}$ & $20,52 \mathrm{~b}$ & $23,29 \mathrm{c}$ & $18,40 \mathrm{a}$ & $-0,0007 \mathrm{x}^{2}+0,0363 \mathrm{x}+21,898$ & 0,46 \\
$\mathrm{C}$ & $10,82 \mathrm{~b}$ & $11,19 \mathrm{~b}$ & $8,95 \mathrm{a}$ & $10,72 \mathrm{~b}$ & $0,0003 \mathrm{x}^{2}-0,0391 \mathrm{x}+11,151$ & 0,27 \\
\hline
\end{tabular}

Médias com letras diferentes na linha apresentam diferenças significativas pelo teste Tukey $(\mathrm{P}<0,05)$. $\mathrm{U}-$ umidade. MS - matéria seca. PB - proteína bruta. EE - extrato etéreo. C - cinzas

A menor porcentagem de extrato etéreo na carcaça foi observada nos alevinos de tambaqui que receberam $100 \%$ de inclusão de farelo de licuri. Esse resultado pode indicar que o farelo de licuri atende melhor às necessidades metabólicas energéticas do tambaqui do que o milho. No entanto, análises metabólicas devem ser feitas para confirmar essa hipótese, além de ser necessário realizar a análise do perfil de ácidos graxos no farelo de licuri e, posteriormente, na carcaça. Fernandes et al. (2010), contudo, comprovam que mesmo rações comerciais que utilizam somente ingredientes convencionais proporcionam carcaças com índices de gordura diferentes. Alevinos de tilápia que se alimentaram de dietas contendo até $100 \%$ de inclusão de triticale em substituição ao milho não apresentaram diferença significativa no conteúdo de gordura na carcaça (Tachibana et al., 2010). De outro modo, alevinos de tilápia que receberam maiores níveis de inclusão de hidrolisado proteico em suas dietas apresentaram maiores níveis de extrato etéreo na carcaça (Leal et al., 2009).

Os valores de cinzas na carcaça foram afetados pelos níveis de substituição do farelo de milho pelo farelo de licuri, no entanto não de forma linear. Diferentemente, o aumento do nível de inclusão de hidrolisado proteico e farelo de nabo forrageiro na dieta diminui o valor de cinzas em carcaça de tilápia (Leal et al., 2009; Santos et al., 2009).

Os valores médios dos parâmetros de qualidade de água estavam dentro dos valores desejáveis para cultivo de alevinos de tambaqui e não afetaram o desempenho dos animais (SipaúbaTavares, 1995). A média do oxigênio dissolvido foi de: $7,3 \mathrm{mg} \cdot \mathrm{l}^{-1} ; \mathrm{pH}: 7,5$; temperatura: $28,7^{\circ} \mathrm{C}$.

\section{CONCLUSÕES}

Pode-se afirmar, de forma conclusiva, que o farelo de milho pode ser substituído em até $100 \%$ por farelo de licuri em dietas para alevinos de tambaqui até o peso de 30 gramas, sem que haja perda no desempenho dos animais. No entanto, sugere-se que mais experimentos devem ser realizados, a fim de se avaliarem alguns parâmetros metabólicos e bioquímicos, bem como experimentos de desempenho com animais em tamanhos maiores.

\section{REFERÊNCIAS}

CAMPECHE, D.F.B.; PEREIRA, L.A.; FIGUEIREDO, R. et al. Limnological parameters and phytoplankton in fish ponds with tambaqui, Colossoma macropomun (Cuvier, 1861) in the semiarid region. Acta Limnol. Brasilien., v.21, p.333-341, 2009.

CORREA, C.F.; AGUIAR, L.A.; LUNDSTED, L.M.; MORAES, G. Response of digestive enzymes of tambaqui (Colossoma macropomum) to dietary cornstarch changes and metablic inferences. Comparative Biochemistry and Physiology A - Mol. \& Integ. Physiol., v.147, p.857-862, 2007.

CRUZ, W.D.; MIGUEL, C.B.; BONIFÁCIO, A.D. et al. Resíduo de cervejaria na alimentação de tambaqui, Colossoma macropomum (Cuvier, 1818). Bol. do Instit. de Pesca, v.24, p.133-138, 1997.

CYRINO, J.E.P.; URBINATI, E.C.; FRACALOSSI, D.M.; CASTAGNOLLI, N. Tópicos especiais em piscicultura de água doce tropical intensiva. São Paulo: TecARt, 2004. 533p.

DAVIS, L.K.; FOX, B.K.; LIM, C. et al. Effects of 11ketosterone and fishmeal in the feed on growth of juvenile tilapia (Oreochromis mossambicus). Aquaculture, v.305, p.143-149, 2010. 
FERNANDES, T.R.C.; DORIA, C.R.C.; MENEZES, J.T.B. Características de carcaça e parâmetros de desempenho do tambaqui (Colossoma macropomum, CUVIER, 1818) em diferentes tempos de cultivo e alimentado com rações comerciais. Bol. do Instit. Pesca, v.36, p.45-52, 2010.

GUIMARÃES, S.F.; STORTI-FILHO, A. Produtos agrícolas e florestais como alimento suplementar de tambaqui em policultivo com jaraqui. Pesqu. Agrop. Bras., v.39, p.293-296, 2004.

HISANO, H.; PORTZ, L. Redução de custos de rações para tilápia: a importância da proteína. Bahia Agrícola, v.8, p.42-45, 2007.

LEAL, A.L.G.; CASTRO, P.F.; LIMA, J.P.V. et al. Use of shrimp protein hydrolysate in Nile tilapia (Oreochromis niloticus, L.) feeds. Aquaculture International, v.18, p.635-646, 2010.

LIMA, T.V.; CAMPECHE, D.F.B.; PEREIRA, L.A. Caracterização da água de açudes com peixes no semiárido pernambucano. Revista Acadêmica - Cienc. Agr. e Amb., v.7, p.395-405, 2009.

MIRANDA, E.C.; GUIMARÃES, I.G.; CABRAL JUNIOR, C.R.; PINHEIRO, D.M. Desempenho produtivo do tambaqui (Colossoma macropomum) alimentado com farinha de vagem de algaroba em substituição ao milho. PUBVET, v.3, p.1982-1263, 2009.

OLIVEIRA, A.C.B.; MARTINELLI, L.A.; SOARES, M.G.M. et al. Seasonality of energy sources of Colossoma macropomum in a floodplain lakes in the Amazon - lake Camaleão, Amazonas, Brazil. Fisheries Manag. and Ecol., v.13, p.135-142, 2006.
PEZZATO, L.E.; BARROS, M.M.; FURUYA, W.M. Valor nutritivo de alimentos utilizados na formulação de rações para peixes tropicais. Rev. Bras. Zootec., v.38, p.43-51, 2009.

SANTOS, V.G.; FERNANDES JUNIOR, A.C.; KOCH, J.F.A. et al. Desempenho produtivo da tilápiado-Nilo arraçoada com dieta contendo farelo de nabo forrageiro. Bol. do Instit. de Pesca, v.35, p.451-459, 2009

SANTOS, V.G.; FERNANDES JUNIOR, A.C.; $\mathrm{KOCH}$, J.F.A. et al. Composição química $\mathrm{e}$ digestibilidade do farelo de nabo forrageiro para tilápia do Nilo. Rev. Bras. Saúde Prod. Anim., v.11, p.537-546, 2010.

SILVA, P.C.; FRANÇA, A.F.S.; PÁDUA, D.M.C.; JACOB, G. Milheto (Pennisetum americanum) como substituto do milho (Zea mayas) na alimentação do tambaqui (Colossoma macropomum). Bol. do Instit. de Pesca, v.24, p.125-131, 1997.

SILVA, J.A.M.; PEREIRA, M.; PEREIRA, M.I.O. Frutos e sementes consumidos pelo tambaqui, Colossoma macrompum (Cuvier, 1818) incorporados em rações: digestibilidade e velocidade de trânsito pelo trato gastrointestinal. Rev. Bras. Zootec., v.32, p.1815-1824, 2003.

SIPAÚBA-TAVARES, L.H.S. Limnologia aplicada à aquicultura. Jaboticabal: FINEP, 1995. 72p.

TACHIBANA, L.; GONÇALVES, G.S.; GUIMARÃES, I.G. et al. Substituição do milho pelo triticale na alimentação de tilápia-do-Nilo. Rev. Bras. Zootec., v.39, p.241-246, 2010. 